\title{
OS REFLEXOS DA CRISE FINANCEIRA DE 1997 NA ECO- NOMIA BRASILEIRA
}

\author{
$\underline{\text { Thaiza Regina Bahry* }}$
}

\section{INTRODUÇÃO}

A estabilização macroeconômica requer o equilíbrio interno aliado ao equilíbrio externo. O primeiro significa baixas taxas de inflação e manutenção do crescimento econômico e o segundo caracteriza-se pela eliminação de déficits ou superávits insustentáveis em conta corrente.

O programa de estabilização adotado no Brasil, em 1994, estava centrado em medidas que acabaram gerando, ao longo do tempo, no plano interno, desemprego crescente e déficit elevado nas contas públicas. A situação das contas externas, por sua vez, não era diferente, pois a prática de taxa de câmbio valorizada gerou grande desequilíbrio, o que provocou o surgimento de déficits crescentes em conta corrente e, consequentemente, tornou o país dependente do capital externo.

Diante desse quadro, o Brasil tornou-se particularmente sensível à crise financeira internacional que atingiu alguns países asiáticos a partir de julho de 1997. As necessidades de financiamento mostraram-se elevadas para um ambiente de alta volatilidade nos mercados mundiais.

Dessa forma, para evitar que o Brasil fosse afetado por uma crise nas mesmas proporções que a Ásia, sofrendo uma fuga maciça de capitais, o governo elevou a taxa de juros e adotou um pacote de medidas fiscais. Assim, buscase verificar quais foram os impactos, sobre o setor externo e as contas públicas, das medidas adotadas pelo governo ante a crise asiática do segundo semestre de 1997.

* Aluna do Curso de Doutorado em Desenvolvimento Econômico da Universidade Federal do Paraná. thaizare@ sociais.ufpr.br 


\section{O Plano Real antes da CRISE aSiática}

O Plano Real foi diferente dos demais planos de estabilização implementados no Brasil, na medida que conduziu à estabilidade de preços, provocando a estabilidade da taxa cambial nominal. ${ }^{1}$ Esse Plano possuía uma âncora cambial e uma âncora monetária. A possibilidade de a taxa de câmbio funcionar como uma âncora foi criada pela abertura da economia, que iniciou em 1990, elevando a participação dos bens internacionais ${ }^{2}$ no produto real e estabilizando o nível geral de preços. Com relação à âncora monetária, o governo limitou a emissão de reais, isto é, no final de cada trimestre, o banco Central submetia ao Conselho Monetário Nacional uma programação monetária para o trimestre seguinte. Dessa maneira, o governo passou a utilizar-se desses instrumentos como forma de garantir a redução da inflação e a sua manutenção em níveis baixos.

No período imediatamente posterior à reforma monetária, o Banco Central estabeleceu um limite máximo de R \$1,00/US\$1,00 e um limite inferior indefinido para a variação da taxa de câmbio. Essa política ficou conhecida como banda assimétrica. Assim, sempre que o valor de mercado do câmbio alcançasse o teto, o Banco Central se comprometia a vender dólares, mas não interviria caso esse valor se mantivesse em níveis inferiores. A taxa cambial flutuou, sendo formada pela oferta e demanda exercidas por agentes privados. Ao mesmo tempo, praticavam-se taxas domésticas de juros elevadas. Isso acabou gerando uma imensa entrada de capitais externos, proporcionando uma valorização do câmbio que permaneceu numa faixa entre R \$ 0,82/US\$1,00 e R\$ 0,86/US\$1,00, de outubro de 1994 a março de 1995.

1 Conforme PASTORE e PINOTTI (1996, p. 28) "a taxa cambial nominal é o preço, expresso na moeda nacional, de uma unidade de moeda estrangeira e em uma economia aberta determina os preços nominais dos bens internacionais. Já a taxa cambial real é um preço relativo. Quando ela desvaloriza, crescem os preços dos bens internacionais relativamente aos dos bens domésticos, o que eleva a produção doméstica e reduz o consumo de bens internacionais, estimulando as exportações e desestimulando as importações. A estabilidade de preços requer a estabilização, embora não necessariamente a constância, da taxa cambial nominal." Ainda, conforme tais autores, a taxa cambial nominal "é relevante em uma economia aberta, para determinar a dinâmica da inflação a curto prazo, e a taxa cambial real é relevante para determinar o comportamento dos saldos em conta corrente no balanço de pagamentos." (PASTORE; PINOTTI, 1995, p. 34)

2 Bens internacionais podem ser entendidos como aqueles que são produzidos domesticamente e que podem ser importados ou exportados. Já os bens domésticos são aqueles que não podem ser importados nem exportados. Os preços dos bens internacionais só podem ser alterados à medida que se modificam seus preços em dólares ou a taxa cambial, dados os impostos sobre o comércio exterior. Em contrapartida, os preços dos bens domésticos são fixados pela oferta e demanda domésticas. 
Em face da crise ocorrida no México em dezembro de 1994, que acabou ocasionando uma reversão dos fluxos de capitais internacionais do Brasil, em março de 1995 o Banco Central promoveu uma alteração na política cambial. Acertou-se, conforme BACHA (1997, p. 47), que, de tempos em tempos, definir-se-ia uma banda larga para a taxa de câmbio, sendo que, dentro dessa banda, seriam realizadas intervenções diárias, para caracterizar uma mini-banda, praticando pequenas e sucessivas desvalorizações dessas mini-bandas em dias e magnitude preanunciadas. Com a instituição do regime de bandas cambiais, o Banco Central passou a atuar de forma a proporcionar uma desvalorização gradual do Real em relação ao dólar. Tal desvalorização passou a situar-se entre 6 e $7 \%$ ao ano. Na tabela 1, pode-se observar os limites superior e inferior da banda praticados desde a adoção deste mecanismo.

Tabela 1 - MUDANÇAS NAS BANDAS DE FLUTUAÇÃO DO CÂMBIO - BRASIL - 1995-1997

\begin{tabular}{l|r|r|r|r}
\hline \multicolumn{1}{c|}{ DATA } & \multicolumn{4}{c}{ BANDA CAMBIAL } \\
\hline & Limite Inferior & Limite Superior & Spread da Banda & Correção do Piso (\%) \\
\hline 06 mar. 1995 & 0,86 & 0,9 & 4,65 & 3,33 \\
10 mar. 1995 & 0,88 & 0,93 & 5,68 & 6,45 \\
22 jun. 1995 & 0,91 & 0,99 & 8,79 & 7,07 \\
30 jan. 1996 & 0,97 & 1,06 & 9,28 & 7,55 \\
18 fev. 1997 & 1,05 & 1,14 & 8,57 & - \\
\hline
\end{tabular}

FONTES: BRITO (1998, p. 115-130), BANCO CENTRAL (1993, 1997).

A valorização do câmbio, que passou a ser praticada com o intuito de conter a inflação, acabou desencadeando um elevado déficit em transações correntes. A balança comercial tornou-se deficitária, visto que as importações apresentaram crescimento bem mais expressivo que as exportações. ${ }^{3}$ Entretanto, a maior participação no déficit foi da conta de serviços, ${ }^{4}$ como pode ser observado na tabela 2.

$3 \mathrm{O}$ grande crescimento das importações na fase inicial do programa deveu-se à abertura da economia, à valorização constante do câmbio e ao aquecimento da economia, ou seja, havia uma conjuntura econômica favorável proporcionada pelo Plano Real. Isso, de acordo com o BANCO CENTRAL (1994, p. 122), acabou promovendo a elevação da média mensal de importações que, nos nove primeiros meses de 1994, chegaram a US\$2,4 bilhões e, nos últimos três, atingiram a cifra de US\$ 4 bilhões.

4 Conforme PASTORE e PINOTTI (1996, p. 33), "o Brasil é estruturalmente deficitário na conta de serviços, pelo pagamento de juros incidentes sobre o estoque da dívida externa, de fretes e seguros relativos ao comércio de mercadorias e viagens ao exterior." 
Tabela 2 - EVOLUÇÃO DAS TRANSAÇÕES CORRENTES - BRASIL - 1993-1997 (US\$ milhões)

\begin{tabular}{l|r|r|r|r|r}
\hline \multicolumn{1}{c|}{ TRANSAÇÕES CORRENTES } & \multicolumn{1}{c|}{1993} & \multicolumn{1}{c|}{1994} & \multicolumn{1}{c|}{1995} & \multicolumn{1}{c}{1996} & \multicolumn{1}{c}{1997} \\
\hline Balança Comercial - FOB & 13307 & 10466 & -3352 & -5539 & -8372 \\
Exportações & 38563 & 43545 & 46506 & 47747 & 52986 \\
Importações & 25256 & 33079 & 49858 & 53286 & 61358 \\
Serviços (líquido) & -15585 & -14743 & -18594 & -21707 & -27288 \\
Juros & -8280 & -6338 & -8158 & -9840 & -10390 \\
Outros Serviços & -7305 & -8405 & -10436 & -11867 & -16899 \\
Transferências Unilaterais & 1686 & 2588 & 3974 & 2899 & 2216 \\
Transações Correntes & -592 & -1689 & -17972 & -24347 & -33445 \\
\hline
\end{tabular}

FONTE: BANCO CENTRAL (1993-1997).

Com o déficit crescente em transações correntes, tornou-se necessário ao Brasil um maior volume de reservas cambiais para garantir o financiamento de sua posição deficitária perante o exterior, pois apenas dessa forma seria possível continuar praticando tal política cambial. Fazia-se necessária a manutenção de elevados diferenciais entre as taxas de juros internas e externas, de forma a atrair capitais para o país. Assim, a partir da implementação do Plano Real, o Brasil passou a receber um elevado estoque de investimento estrangeiro, ${ }^{5}$ incorrendo num aumento do passivo externo, sendo que sua dependência do capital estrangeiro foi aprofundando-se ao longo do tempo.

Segundo a equipe do governo, apesar do alto custo, a manutenção das reservas em níveis elevados era importante para inibir fatores especulativos ao real, os quais poderiam desencadear uma desvalorização da moeda. A desvalorização poderia significar o retorno da inflação, uma vez que a taxa de câmbio servia como âncora ao Programa de Estabilização. Assim, justificava-se a prática de uma elevação da taxa de juros como forma de atrair capitais externos para o país.

A taxa de juros tornou-se um instrumento passivo, pois a cada oscilação das reservas ocorria também uma oscilação nessa taxa. Entretanto, ao mesmo tempo que esta tinha efeitos benéficos com relação à atração de capitais, provocava elevados déficits nas contas públicas. Com a finalidade de evitar um excesso de liquidez, as autoridades monetárias enxugavam a quantidade excedente de moeda nacional, proporcionada pela entrada de divisas, colocando títulos públicos no mercado. Esses títulos provocavam o aumento da dívida

5 Os investimentos estrangeiros que entravam no país eram investimentos indiretos, atraídos pelas altas taxas de juros, e investimentos diretos, atraídos, em muitos casos, pela existência de empresas e bancos públicos e privados que estavam sendo vendidos a preços baixos. 
mobiliária, que era rolada justamente com as altas taxas de juros que atraíam o capital especulativo estrangeiro. Esse mecanismo gerava uma elevação das despesas financeiras do governo, aumentando o déficit público operacional. ${ }^{6} \mathrm{Na}$ tabela 3, pode-se observar o comportamento das contas públicas entre 1994 e 1997. Percebe-se a eliminação dos superávits e a incorrência em déficits, no período em análise, tanto no conceito primário como no operacional. No conceito nominal, há uma forte redução do déficit dos anos analisados em relação a 1994, o que deve-se à redução da inflação depois da implementação do Plano Real.

Tabela 3 - SALDO DAS CONTAS PÚBLICAS - BRASIL - 1994-1997

\begin{tabular}{c|r|r|r}
\multicolumn{2}{c}{} & \multicolumn{1}{c}{$(\%$ do PIB $)$} \\
\hline ANO & $\begin{array}{l}\text { CONCEITO } \\
\text { PRIMÁRIO }\end{array}$ & $\begin{array}{c}\text { CONCEITO } \\
\text { OPERACIONAL }\end{array}$ & $\begin{array}{c}\text { CONCEITO } \\
\text { NOMINAL }\end{array}$ \\
\hline 1994 & 5,3 & 1,4 & $-45,5$ \\
1995 & 0,4 & $-4,9$ & $-7,2$ \\
1996 & $-0,1$ & $-3,7$ & $-5,9$ \\
1997 & $-0,9$ & $-4,3$ & $-6,1$ \\
\hline
\end{tabular}

FONTE: BANCO CENTRAL. (1993-1997).

Nota: Os valores com sinal negativo representam déficits e os valores positivos, superávits.

O déficit de $-45,5 \%$ no conceito nominal, em 1994, deve-se à alta taxa de inflação que perdurava no país antes do Plano Real.

Assim, o desequilíbrio interno, juntamente com o desequilíbrio externo, passou a agravar-se ano a ano. Essa situação deveu-se ao grande objetivo do governo de reduzir a inflação e mantê-la baixa a qualquer custo, objetivo este que foi atingido, conforme mostra a tabela 4.

6 No conceito primário das contas públicas, estão excluídos os dispêndios com juros e correção monetária. No conceito operacional, estão incluídas as despesas com juros e excluída a correção monetária. E, no conceito nominal, estão incluídas as despesas com juros e correção monetária. 
Tabela 4 - EVOLUÇÃO DO IGP-DI EM 12 MESES - 1993-1997

\begin{tabular}{lr}
\hline \multicolumn{1}{c|}{ ANO } & EVOLUÇÃO DO IGP-DI \\
\hline 1993 & 2708,55 \\
1994 & 909,61 \\
1995 & 14,78 \\
1996 & 9,34 \\
1997 & 7,48 \\
\hline
\end{tabular}

FONTE: BANCO CENTRAL (1993-1997).

Mas a persistência, no longo prazo, de baixas taxas de inflação ficava comprometida, em função de que isso só havia se conseguido com o agravamento dos desequilíbrios externo e interno, situação esta que tornara-se insustentável ao longo do tempo.

O real tinha como condição necessária a sua manutenção, a disponibilidade de fluxos externos para financiá-lo, e isso acabava tornando o país suscetível a crises, em função da volatilidade dos fluxos internacionais de capitais. Neste sentido, há forte evidência de que o governo brasileiro subestimou o perigo de depender em grande escala do capital externo, não acreditando que uma crise mundial pudesse eclodir.

Com a crise deflagrada na Ásia, as expectativas dos agentes mudaram e as dúvidas relativas à estabilidade cambial dos países com elevados déficits em transações correntes acirraram-se. Assim, os capitais destinados a tais países sofreram retração. O Brasil tornou-se particularmente sensível a essa crise, pois suas necessidades de financiamento mostraram-se elevadas para um ambiente de tão alta volatilidade nos mercados mundiais.

\section{A ECONOMIA BRASILEIRA DIANTE DA CRISE ASIÁTICA}

A crise desencadeada na Ásia proporcionou perdas patrimoniais intensas no resto do mundo. Essa crise que se abateu sobre as bolsas de valores das mais diversas regiões do planeta causou uma fabulosa redução da riqueza financeira. Começando por alguns países da Ásia, a crise contaminou os negócios de outras economias, transformando a instabilidade regional em mundial. ${ }^{7}$

7 Atualmente, dada a interdependência existente entre as economias nacionais, as crises localizadas têm grande facilidade de se difundir internacionalmente. 
Na América Latina, o país mais atingido foi o Brasil, sendo que a queda apresentada na bolsa de valores esteve aproximadamente nas mesmas proporções das registradas pelas economias asiáticas. ${ }^{8}$

A fuga de capitais do Brasil, deu-se por, pelo menos, dois motivos: atendimento das necessidades de liquidez dos aplicadores estrangeiros ${ }^{9}$ e percepção de que o país poderia ter que desvalorizar o real, antes mesmo que a fuga de capital comprometesse o volume de reservas.

O Brasil foi "pego" pela crise numa situação vulnerável. Os elevados déficits em transações correntes e nas contas públicas colocaram-no numa situação particularmente sensível diante da crise internacional.

Com a forte fuga de capitais, a partir da queda das bolsas de Hong Kong, num primeiro momento de combate à crise, o governo utilizou-se de instrumentos cambiais, desfazendo-se de elevado volume de reservas para evitar uma desvalorização. Entretanto, num ambiente de tamanha aversão ao risco e retração da liquidez, os instrumentos de natureza cambial não são suficientes para evitar o sucesso de um ataque especulativo. Assim, em 30 de outubro, o governo elevou o cupom cambial, ${ }^{10}$ via aumento das taxas internas de juros, visando o estancamento da saída das reservas e iniciando um rápido esfriamento da economia. Mesmo com essa medida, os investidores não foram tranqüilizados, pois tanto as fugas de capital como a demanda por hedge continuaram.

Para restabelecer a confiança dos investidores na capacidade do governo brasileiro de sustentar a moeda contra um ataque especulativo, como primeiro movimento estratégico, tornou-se imperativo promover uma contração fiscal, buscando produzir um expressivo resultado primário. Mediante esta situação, o governo anunciou, em 10 de novembro, um abrangente conjunto de

8 Conforme a revista Businees Week (1997, p. 53), "uma semana após o crash asiático, os principais mercados acionários do Mundo contabilizaram os prejuízos: Hong Kong, -35,4\%; Japão, -21,3\%; EUA, -9,1\%; Grã-Bretanha, -9,2\%; Austrália, -12,1\%; México, -10,1; e Brasil, $27,9 \%$."

9 Os investidores em ações nas bolsas realizam operações também em mercados futuros, "apostando" em variações nos preços desses papéis. Como o colapso ocorrido nas bolsas asiáticas não foi previsto a tempo, as expectativas otimistas sobre o comportamento das ações não se confirmaram e os investidores foram levados a se desfazer das ações que possuíam em outras bolsas para cobrir os prejuízos obtidos na Ásia.

10 Conforme ALMEIDA (1998, p. 75), "no jarguão financeiro, o termo cupom cambial refere-se aos ganhos adicionais que os proprietários de divisas internacionais obtêm ao aplicálas em ativos nominados em uma moeda específica - no caso o real. Os referidos ganhos adicionais, no momento da aplicação, são calculados com base na diferença entre as taxas internas e as externas de juros, descontando-se a variação cambial prevista para a moeda na qual a operação é 
medidas que visava acelerar o ajuste fiscal ao longo de 1998. O segundo movimento estratégico do governo era a redução, no curto prazo, dos déficits em transações correntes, mediante a redução temporária das importações, de uma política de incentivo às exportações e da redução das despesas relacionadas às viagens internacionais. Adotaram-se, ainda, medidas com o objetivo de melhorar o financiamento deste déficit, ou seja, buscava-se financiá-lo com capitais de melhor qualidade. $\mathrm{O}$ terceiro passo seria a continuidade do processo de reestruturação produtiva, mediante a vinculação da economia nacional à internacional. Com a reestruturação produtiva, o governo esperava dinamizar as exportações, reduzindo os déficits em transações correntes, o que fortaleceria os mecanismos que garantiam as estabilidades cambial e monetária.

As medidas adotadas foram consideradas, pela equipe econômica, como necessárias e indispensáveis para enfrentar a conjuntura internacional que se fazia presente. Defendia-se que, salvo um aprofundamento da crise internacional, com o conjunto de medidas adotadas, o país sairia do período de instabilidade com suas condições de crescimento e estabilidade revigoradas.

\section{OS EFEITOS DAS MEDIDAS ADOTADAS PELO BRASIL FRENTE À CRISE ASIÁTICA}

As medidas adotadas para enfrentamento da crise asiática dissiparam as incertezas quanto à desvalorização ou não da moeda e, no segundo semestre de 1997, o governo continuou adotando o regime de bandas cambiais com minidesvalorizações, ${ }^{11}$ adotado em março de 1995 . Tais medidas tiveram êxito em sustentar a taxa de câmbio, embora os efeitos não tenham sido muito benéficos em outras variáveis macroeconômicas.

Com relação ao déficit em transações correntes, confrontando o segundo semestre de 1997 com o mesmo período de 1996, constata-se que a grande responsável pelo aumento do déficit foi a conta de serviços. Observando-se os dois períodos, na tabela 5, percebe-se que houve redução no déficit comercial, proporcionada por um crescimento de $13,51 \%$ das exportações e de $9,14 \%$ das importações. Já na conta de serviços houve um crescimento do déficit em $28,51 \%$. Por outro lado, comparando-se o primeiro semestre de 1998 com o mesmo período de 1997, pode-se também observar uma redução do déficit co-

nominada."

11 A banda de flutuação do câmbio sofreu alteração em seus parâmetros somente em 20 de janeiro de 1998 , quando o limite inferior passou de R\$ 1, 05/US\$1,00 para R \$1,12/US\$ 
mercial, resultado do crescimento das exportações $(4,77 \%)$ e do decréscimo das importações $(1,6 \%)$. A conta de serviços cresceu 4,01\%, bem menos expressivo que o período comparado anteriormente. Nesse sentido, houve uma redução no déficit em transações correntes no período analisado. Essa redução se torna bem mais expressiva comparando-se o primeiro semestre de $1998 \mathrm{com}$ o segundo semestre de 1997. Pela análise, conclui-se que, embora as medidas adotadas pelo governo não apresentaram os efeitos esperados, houve sensível melhora na balança comercial. A conta de serviços continuou sendo a maior responsável pelo déficit em transações correntes e o país continuou necessitando de elevado volume de recursos externos para financiar seu déficit (tabela 5).

Tabela 5 - TRANSAÇÕES CORRENTES - BRASIL - 1996-1998

\begin{tabular}{lrrr|r|r}
\hline \multicolumn{1}{c}{ DISCRIMINAÇÃO } & $2^{\circ}$ SEM. 1996 & $1^{\circ}$ SEM. 1997 & $2^{\circ}$ SEM. 1997 & $1^{\circ}$ SEM. 1998 \\
\hline Balança Comercial - FOB & -5228 & -3752 & -4620 & -2113 \\
Exportações & 24844 & 24786 & 28200 & 25969 \\
Importações & 30072 & 28538 & 32820 & 28082 \\
Serviços (líquido) & -11691 & -12264 & -15024 & -12756 \\
Juros & -4658 & -4505 & -5884 & -4831 \\
Outros Serviços & -7033 & -7759 & -9140 & -7925 \\
Transferências Unilaterais & 1304 & 1164 & 1052 & 916 \\
Transações Correntes & -15616 & -14852 & -18592 & -13953 \\
\hline FONTE: BANCO CENTRAL (1997-1988). & & & &
\end{tabular}

(1) Inclui lucros reinvestidos

Referindo-se ao financiamento desse déficit, pode-se verificar, na tabela 6, que, no primeiro semestre de 1998, houve um expressivo crescimento da proporção do déficit financiado por investimentos diretos em relação ao semestre imediatamente anterior. Esse fato é explicado, não pelo crescimento da entrada de investimentos diretos no país, mas pela redução ocorrida no déficit no primeiro semestre de 1998. Nesse sentido, no período em análise, as medidas adotadas pelo governo visando promover a entrada em maior quantidade de capitais de longo prazo no país, para melhorar a qualidade do financiamento do déficit, não tiveram o resultado esperado. 


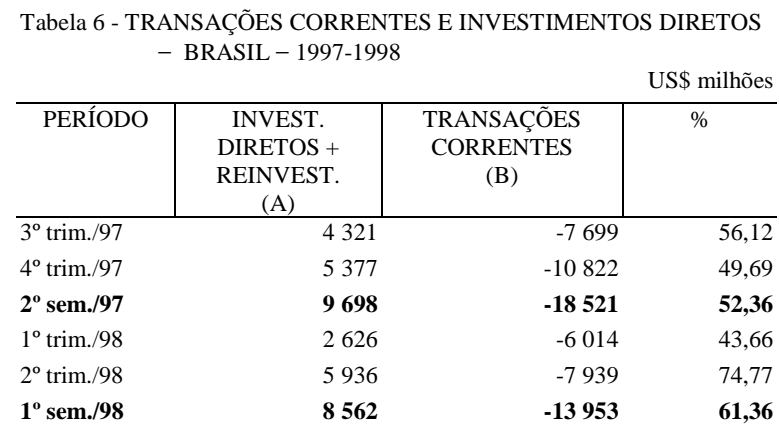

FONTE: BANCO CENTRAL (1997-1988).

A elevação da taxa de juros, no final de outubro, conseguiu estancar a saída de recursos do país, mas, ao mesmo tempo, incidiu sobre as contas do governo, aumentando o montante de juros pagos por este. Dessa forma, as medidas adotadas pelo governo frente à crise asiática, visando reverter a deterioração das contas públicas ocorrida depois do Plano Real, não apresentaram o resultado esperado. Isso porque a elevação da taxa de juros ${ }^{12}$ piorou a situação do resultado nominal. Com relação ao resultado primário, verifica-se que foi pior em 1998, havendo redução do superávit, o que deveu-se ao desequilíbrio existente nas contas da Previdência Social ${ }^{13}$ (tabela 7).

1,00 e o superior passou de R \$1,14/US\$1,00 para R \$ 1,22/US\$1,00.

12 A taxa de juros passou a sofrer redução já a partir de novembro de 1997. Entretanto, como tal redução era gradual, apenas em junho de 1998 esta taxa atingiu um patamar próximo a setembro de 1997.

13 Nesse sentido, vale salientar que, de acordo com dados levantados do Banco Central, enquanto, de janeiro a julho de 1997, o INSS registrou um déficit de 0,03\% do PIB, no mesmo período de 1998, esse déficit chegou a 0,49\% do PIB. Isso significa que o déficit da Previdência, nos primeiros sete meses de 1998, foi equivalente a 16,33 vezes o que tinha sido em igual período no ano anterior. Até julho de 1998, a Previdência Social já tinha apresentado um déficit superior 
Tabela 7 - COMPORTAMENTO DAS CONTAS BANCÁRIAS - BRASIL - 1997-1998

\begin{tabular}{|c|c|c|c|c|}
\hline \multirow[t]{3}{*}{ DISCRIMINAÇÃO } & \multicolumn{4}{|c|}{ Necessidades de financiamento do setor público ${ }^{(1)}(\mathrm{em} \%$ do PIB $)$} \\
\hline & \multicolumn{2}{|l|}{1997} & \multicolumn{2}{|c|}{1998} \\
\hline & Jan.-Jul. & Ano & Jan.-Jun. & Jan.-Jul. \\
\hline Nominal & 4,16 & 6,09 & 7,27 & 7,02 \\
\hline Juros nominais & 5,06 & 5,18 & 7,41 & 7,29 \\
\hline Primário & $-0,9$ & 0,91 & $-0,14$ & $-0,28$ \\
\hline
\end{tabular}

FONTE: Gazeta Mercantil, 14 out.1998, p. A-8

NOTA: Dados preliminares.

Os valores com sinal positivo representam déficits, e os negativos, superávits.

(1) Reflete a relação dos fluxos com o PIB, ambos valorizados para o último mês do período com base no IGP-DI.

(2) Inclui o INSS.

Mesmo diante da crise asiática, o grande objetivo do Plano Real, taxas de inflação baixas, não sofreu abalos. Desde julho de 1997, quando a Ásia começou a ser atingida pela instabilidade financeira, até junho de 1998, o índice de inflação sofreu algumas oscilações. Entretanto, durante todo esse período, manteve-se em níveis baixos, tendo permanecido em níveis inferiores a $1 \%$ ao mês, como pode-se observar na tabela 8 .

\begin{tabular}{l|r} 
Tabela 8 - VARIAÇÕES DO IGP-DI - JULHO \\
\multicolumn{2}{c}{ 1997 - JUNHO 1998 } \\
\hline \multicolumn{1}{c}{ MÊS } & \multicolumn{2}{c}{ EVOLÇÃO DO IGP- } \\
& DI \\
\hline 1997 & 0,09 \\
Julho & $-0,04$ \\
Agosto & 0,59 \\
Setembro & 0,34 \\
Outubro & 0,83 \\
Novembro & 0,69 \\
Dezembro & \\
1998 & 0,88 \\
Janeiro & 0,02 \\
Fevereiro & 0,23 \\
Março & $-0,13$ \\
Abril & 0,23 \\
Maio & 0,28 \\
Junho & \\
\hline FONTE: Gazeta Mercantil. &
\end{tabular}


Na realidade, o governo utilizou-se da taxa de câmbio, ou seja, manteve a mesma nos níveis em que se encontrava, sem praticar uma desvalorização, com vistas a assegurar seu objetivo maior: a estabilidade de preços. Entretanto, conforme salientado anteriormente, com os desequilíbrios externo e interno crescentes, a manutenção da taxa de inflação, nos níveis em que ela se encontrava, tornava-se incerta.

A continuidade no longo prazo de tais desequilíbrios abala a confiança dos credores, tornando necessária a ocorrência de uma desvalorização cambial. A inflação brasileira foi reduzida e mantida em níveis baixos mediante a elevação dos custos relativos dos bens e serviços brasileiros. Essa situação apenas podia ser mantida ao continuar-se mantendo a taxa de câmbio valorizada, sendo que, para isso, dependia-se de um elevado nível de reservas, o que apenas poderia ser mantido com a sustentação da confiança dos investidores estrangeiros no Brasil.

As medidas adotadas pelo governo brasileiro após a crise asiática tinham como finalidade o restabelecimento da confiança de tais investidores. Isso asseguraria a continuidade do fluxo de capitais externos para o país, garantindo o financiamento das posições deficitárias, evitando uma desvalorização da moeda. Esta, acreditava-se, poderia gerar um novo surto inflacionário no país, ou seja, naquele momento, corria-se o risco de uma pequena desvalorização desencadear desvalorizações sucessivas, como ocorreu no México em 1994. ${ }^{14}$

O Brasil tornou-se sensível à crise em função da grande e persistente valorização cambial relacionada ao Plano Real, que vinha sendo corrigida de forma muito lenta. Em síntese, a adoção, no início do Plano Real, de uma taxa de câmbio que podia variar livremente até o limite de R $\$ 1,00 / \mathrm{US} \$ 1,00$, aliado à prática de uma taxa de juros doméstica maior que a internacional, que provocava elevados fluxos de capital para o Brasil, provocou uma valorização da moeda brasileira, o que tornou os produtos domésticos mais caros que os internacionais, reduzindo o emprego e gerando uma elevação do déficit em transações correntes. Apesar da mudança da política cambial, em março de 1995, a valorização da moeda persistiu, o que mantinha a pressão altista do déficit em transações correntes. Esse déficit tinha que ser financiado com a entrada de capitais externos, em razão da insuficiência de poupança interna. Para atrair tais capitais externos, continuava-se tendo que praticar taxa de juros elevada. Assim, esta taxa incidia sobre as contas públicas, elevando o seu valor, o que

ao do ano inteiro de 1997.

14 No México, em 19 de dezembro de 1994, o governo anunciou uma desvalorização de $15 \%$, a primeira em sete anos. Três dias depois, apesar da elevação da taxa de juros que havia 
provocava desequilíbrio interno. E, quanto mais elevado o valor da dívida pública, maior o risco do país e mais elevada deve ser a taxa de juros oferecida aos investidores. Essa taxa de juros elevada desestimula o investimento, reduz a demanda agregada e acaba colocando o país em uma recessão. Assim, a manutenção da inflação em um nível baixo deu-se às custas de um elevado desequilíbrio interno e de um desequilíbrio externo. O país acabou se encontrando numa situação de déficit externo com recessão. Essa situação é de dilema de política econômica, ou seja, à medida que o governo tenta resolver o problema do déficit acentua a recessão, e quando tenta resolver o problema da recessão provoca um crescimento do déficit. ${ }^{15}$

Em outubro de 1997, quando a crise asiática atingiu o seu auge, conforme os modelos de crise de Paul Krugman, o Brasil tinha todos os ingredientes necessários para sofrer uma crise de segunda geração. ${ }^{16}$ Nesse sentido, pela análise feita até junho de 1998, pode-se constatar que as medidas adotadas frente à crise não foram eficazes para reverter esse quadro. Assim, o governo continuava apresentando alguns motivos para manter o regime de taxa de câmbio adotado, isto é, o regime de bandas que se aproximava do câmbio fixo. O grande argumento usado pelo governo era que, se abandonasse tal regime, proporcionaria o retorno da inflação. Ou seja, como o país havia saído há pouco tempo de um longo período de convívio com índices de inflação elevados, se permitisse uma flutuação do câmbio e este viesse a sofrer desvalorização, poderia ocorrer o retorno da inflação. Ao mesmo tempo, haveria uma perda de credibilidade do país perante o exterior e a tão almejada reestruturação produtiva, que estava sendo facilitada com a importação de bens de capital por preços mais baixos, encontraria dificuldades em ser finalizada. Outro argumento é que, em um ambiente de instabilidade financeira, deixar o câmbio flutuar poderia provocar

ocorrido no dia 21, a desvalorização acumulada já atingia 32\% em relação ao dólar.

$15 \mathrm{O}$ dilema se dá de forma que, por exemplo, para solucionar o problema de desemprego, deve-se praticar uma política expansionista, mas para resolver o problema do déficit exigese uma contração.

16 Conforme KRUGMAN (1997), existem três modelos de geração de crise. No modelo de primeira geração, analisa-se a crise como uma causa do déficit fiscal que é financiado com emissão de moeda e em regime de taxa de câmbio fixo. Um governo com déficits persistentes do orçamento, financiados com dinheiro, usa um estoque limitado de reservas para fixar sua taxa de câmbio. Isso, em última instância, torna-se insustentável, e os investidores atacam a moeda. No modelo de segunda geração, existe um trade-off entre a flexibilidade macroeconômica de curto prazo, isto é, o nível de emprego, e a credibilidade gerada a longo prazo pela paridade fixa. Nesse caso, o governo não se compromete a vender reservas indefinidamente. Os agentes podem atacar a moeda caso identifiquem que o custo de manter a paridade é elevado ou que a paridade é insustentável. No modelo de terceira geração, a crise é eminentemente financeira, surgindo um grave problema de riscos morais, quando não existem controles eficazes dos intermediários financeiros 
uma forte desvalorização da moeda, em níveis superiores aos esperados pelo governo. Por outro lado, o país possuía motivos para deixar o câmbio flutuar, entre os quais, conforme visto, estava o grande ônus da dívida pública, denominada em moeda nacional, o elevado déficit em transações correntes acumulado após o Plano Real e o nível crescente de desemprego a que o país estava submetido. Por fim, para completar as condições necessárias para a realização de uma crise de segunda geração, a desconfiança dos agentes de que a taxa de câmbio não seria mantida no patamar em que se encontrava exigia do governo a prática de elevadas taxas de juros, o que enfraquecia ainda mais a produção e o emprego no país.

As medidas adotadas pelo governo depois da crise asiática não foram eficazes em proporcionar ao país transcender a estabilização macroeconômica de curto prazo, reduzindo a vulnerabilidade externa. Na verdade, essas medidas conseguiram evitar uma desvalorização da moeda naquele momento, mas não melhoraram a situação das outras variáveis macroeconômicas necessárias para evitar uma desvalorização mais adiante e possibilitar ao país ingressar em uma fase de desenvolvimento sustentado.

No cenário de instabilidade financeira internacional, a Rússia acabou desvalorizando sua moeda, o rublo, e, em 17 de agosto de 1998, anunciou moratória. Diante desse agravamento da situação financeira internacional, o Brasil, que era um país considerado de grande risco pelos investidores estrangeiros, começou a anunciar medidas sucessivas para conter a saída de dólares. ${ }^{17}$ As medidas contiveram, ao menos temporariamente, a fuga de capitais. Entretanto, a dependência do capital externo, associada à falta de ação concreta no combate ao déficit público e ao déficit em transações correntes, deixou o país em enormes dificuldades. Mais tarde, acabou recorrendo à ajuda financeira do FMI, recebendo um empréstimo de US\$ 41,5 bilhões.

e os investidores percebem garantias implícitas do governo.

17 Inicialmente o governo aumentou o volume de títulos públicos com correção cambial no mercado, reduziu os prazos médios mínimos dos empréstimos externos e permitiu que o dinheiro captado por bancos para repasse à agricultura fosse para títulos públicos com correção cambial. Essas medidas foram seguidas por um estímulo à entrada de capitais, mediante a isenção de Imposto de Renda às aplicações em fundos de renda fixa de estrangeiros. Como a saída de dólares continuava, o Comitê de Política Monetária (Copom) reduziu a Taxa Básica do Banco Central (TBC) de 19,75\% para 19\%, mas elevou a Taxa de Assistência do BC (Tban) de 25,75\% para $29,75 \%$. Depois o governo fechou a linha TBC, mantendo apenas a Tban, o que, na prática, elevou os juros primários para $29,75 \%$, deixando clara a manutenção da política cambial em vigor e a opção pela linha ortodoxa de reação à crise. Em seguida o governo anunciou o compromisso com superávit primário de R \$ 5 bilhões em 1998 e de R \$ 8,7 bilhões para 1999 e criou uma comissão para fazer cumprir as metas. Por fim, como o mercado reagiu com ceticismo, o governo elevou a Tban para 49,75\%, em 10 de setembro de 1998. 
O pacote de ajuda não foi suficiente para evitar uma crise no Brasil e, em janeiro de 1999, o país começou a sofrer diversos ataques especulativos, as bolsas começaram a sofrer fortes quedas, as reservas cambiais começaram a cair a níveis considerados críticos e o governo, inicialmente, anunciou uma desvalorização do câmbio de $8 \%$. Como isso não conteve a fuga de capitais e como o país estava perdendo muitas reservas na intervenção para manter a taxa cambial, ainda nesse mês abandonou-se o regime de bandas cambias e possibilitouse a flutuação do câmbio.

\section{CONCLUSÃo}

As medidas adotadas pelo governo diante da crise asiática não foram eficazes em reverter a situação de fragilidade externa e das contas públicas. $\mathrm{O}$ país, em junho de 1998, encontrava-se numa situação de deterioração crescente de suas contas.

A valorização do real, se necessária no início do Plano para conter a inflação, foi um erro no médio prazo, na medida que acabou gerando elevados déficits externos. Como o Brasil não possuía poupança interna, a necessidade de cobrir os déficits acabou levando o país a recorrer às reservas cambiais (poupança externa), que no caso brasileiro eram formadas majoritariamente por capital volátil. Para manter as reservas, tornou-se necessária a prática de uma taxa de juros elevada, pois o risco brasileiro era elevado à medida que a dívida pública apresentava uma trajetória explosiva.

A dependência de capital externo a que o Plano Real submeteu o Brasil tornou-se extremamente problemática em uma situação de instabilidade financeira internacional. Em 1994, quando o México foi atingido por uma crise, o Brasil teve o primeiro aviso de que déficits elevados em conta corrente eram insustentáveis no longo prazo. Naquele momento, o governo brasileiro tentou reverter a situação. Entretanto, passado algum tempo, e com a volta da normalidade financeira internacional, os gestores de política econômica do país desconsideraram a crise mexicana e continuaram centrando a política na dependência do capital externo, não acreditando em novas crises mundiais.

Dessa forma, em 1997, quando a instabilidade atingiu a Ásia, o Brasil encontrava-se numa posição de fragilidade muito maior do que em 1994 e com enormes dificuldades para reverter o quadro de dependência. Em suma, podese afirmar que as medidas adotadas pelo governo naquela ocasião não foram suficientes para evitar o contágio, apenas serviram para postergá-lo. Na verdade, tais medidas significaram a continuidade de um percurso que levaria o país às portas do FMI e, em janeiro de 1999, à desvalorização cambial pelo mercado. 


\title{
RESUMO
}

Este artigo busca analisar quais foram os efeitos, sobre as contas públicas e o setor externo da economia brasileira, das medidas adotadas pelo governo para evitar que o Brasil fosse contagiado por uma crise nas mesmas proporções que a Ásia. Inicialmente, mostra-se o comportamento da economia brasileira desde que o Plano Real foi implementado até julho de 1997, quando iniciou a crise na Ásia. Logo a seguir, mostram-se as medidas adotadas pelo governo para evitar a crise no Brasil. E, por fim, analisam-se as conseqüências de tais medidas sobre a economia brasileira até junho de 1998.

\begin{abstract}
This paper intends to analyze which were the implications, over both the Brazilian public budget and the balance of payments from the policy made by the government, after the Asian's Crisis in 1997. First it shows the performance of the Brazilian economy since the government introduced the Real Plan in 1994 until the Asian's Crisis. After that, it shows what the government made to avoid the crisis to be spreaded all over Brazil. Finally, it adresses the performance of the Brazilian economy after this crisis, until mid 1998.
\end{abstract}

\section{REFERÊNCIAS}

ALMEIDA, Pedro Fernando da C. No vôo da economia brasileira, pilotar é preciso? Indicadores Econômicos FEE, Porto Alegre, v. 26, n. 1, p. 66-101, 1998.

BACHA, Edmar L. O Plano Real: uma avaliação. In: MERCADANTE, Aloisio (Org.). O Brasil pós-Real: a política econômica em debate. Campinas: Unicamp/Instituto de Economia, 1997. p. 11-69.

BANCO CENTRAL. Relatório anual. Brasília, 1993-1997.

BANCO CENTRAL. Boletim Mensal. Brasília, 1997-1998. 
BAHRY, Thaiza R. Os reflexos da crise financeira de 1997 na economia brasileira. Ijuí: Unijuí, 1999. 118 p. (Coleção trabalhos acadêmico-científicos. Série dissertações de mestrado).

BARI, Mamadu Lamarana. Três anos de Plano Real: uma reflexão sobre a política econômica do governo no contexto da globalização. In: MERCADANTE, Aloízio (Org.). O Brasil pós-Real: a política econômica em debate. Campinas: Unicamp/Instituto de Economia, 1997. p. 283-291.

BATISTA JUNIOR, Paulo Nogueira. Inconsistência e populismo na política econômica brasileira. In : LANDI, Mônica (Org.). Setor externo: os impasses da política cambial. São Paulo: Educ, 1997. p. 59-67.

BELLO, Teresinha da Silva. A política econômica frente aos desafios do setor externo. Indicadores Econômicos FEE, Porto Alegre, v. 25, n. 3, p. 81-97, nov. 1997.

BM\&F. Rio de Janeiro: Bolsa de Mercadorias \& Futuros.

BRAZIL's nervous neighbors. Business Week, p. 64-65, 17 nov. 1997.

BRITO, Marcio Holland. Taxa de câmbio e regimes cambiais no Brasil. Campinas, 1998. Tese (Doutorado em Economia) - Instituto de Economia e Aplicadas, Universidade Estadual de Campinas. p. 115-130.

CONSIDERA, Claudio Monteiro. A segunda provação externa. Folha de S. Paulo, 08 nov. 1997, p. 3.

DORNBUSCH, Rudiger. Brazil's incomplete stabilization and reform. 1997. Mimeog.

DORNBUSCH, Rudiger; FISCHER, Stanley. Macroeconomia. 5. ed. São Paulo: Makron, Mc. Graw-Hill, 1991. Caps. 4, 6, 14, 20.

FERREIRA, Carlos Kawall L. Um ataque especulativo contra o Real? In: LANDI, Mônica (Org.). Setor externo: os impasses da política cambial. São Paulo: Educ, 1997. p. 69-88.

FISHLOW, Albert. Is the Real Plan for real? 1997. Mimeog.

FLIGENSPAN, Flavio Benevett. Uma visão global da economia brasileira durante a vigência do Plano Real: avanços, impasses e um cenário de crescimento com exclusão. Indicadores Econômicos FEE, Porto Alegre, v. 26, n. 1, p. 102-143, 1998.

FOLHA DE S. PAULO, São Paulo, set. 1998 - fev. 1999.

FRANCO, Gustavo H. B. A inserção externa e o desenvolvimento. Brasília: BACEN, 1996. Mimeog.

FRANCO, Gustavo H. B. O Plano Real e outros ensaios. Rio de Janeiro: F. Alves, 1995.

GAZETA MERCANTIL, São Paulo, jul. 1998-fev. 1999.

GONÇALVES, Reinaldo. Desestabilização macroeconômica e incertezas críticas: o governo FH e suas bombas de efeito retardado. In: MERCADANTE, Aloízio (Org.). O Brasil pós-Real: a política econômica em debate. Campinas: Unicamp/Instituto de Economia, 1997. p. 169-194.

ÍNTEGRAS das medidas divulgadas. Gazeta Mercantil, São Paulo, 13 nov. 1997. Ajuste Fiscal, p. 1-12.

KANDIR, Antonio. A resposta do Brasil à crise. Folha de S. Paulo, 23 nov. 1997. 
KRUGMAN, Paul. Currency crises. Disponível em: 〈http://web.mit.edu/krugman/www〉 Preparado para NBER conference, out. 1997a.

KRUGMAN, Paul. Não precisamos perder o sono. Exame, São Paulo, ano 31, n. 8, 08 abril 1998.

LIMA, José Humberto Silva. Resgate da moeda: da origem ao Real. In: MERCADANTE, Aloísio (Org.). O Brasil pós-Real: a política econômica em debate. Campinas: Unicamp/Instituto de Economia, 1997. p. 293-307.

MINISTÉRIO DA FAZENDA. Exposição de motivos da MP do Plano Real. Disponível em: <http://161.148.1.151/português/real/redem.html>

O AJUSTAMENTO ao choque externo. Carta de Conjuntura, Rio de Janeiro, n. 76, p. 1-8, nov. 1997.

OLIVEIRA, Gesner. Brasil Real: desafios da pós-estabilização na virada do milênio. São Paulo: Mandarim, 1996.

PASTORE, Affonso; PINOTTI, Maria C. Câmbio e inflação. In: VELOSO, João Paulo dos R. (Coord). O Real e o futuro da economia. Rio de Janeiro: J. Olympio, 1995. p. 31-44.

PASTORE, Affonso; PINOTTI; Maria C. O futuro do Real: o uso das políticas fiscal e monetária para a estabilização interna e externa. In: VELLOSO, João Paulo dos R. (Coord.). O Real, o crescimento e as reformas. Rio de Janeiro: J. Olympio, 1996. p. 25-48.

SALDANHA JUNIOR. Roland Veras. Desvalorização cambial: problema econômico? In: LANDI, Mônica (Org.). Setor externo: os impasses da política cambial. São Paulo: Educ, 1997. p. 59-67.

SAYAD, João. Observações sobre o Plano Real. In: MERCADANTE, Aloisio (Org.). O Brasil pós-Real: a política econômica em debate. Campinas: Unicamp/Instituto de Economia, 1997. p. 71-88.

TEIXEIRA, Marco Aurélio. Mercados Futuros: fundamentos e características operacionais. São Paulo: Bolsa de Mercadorias \& Futuros, [199?]. 